\title{
UNSOUNDNESS IN HORSES
}

Richard Lawrence

1809 


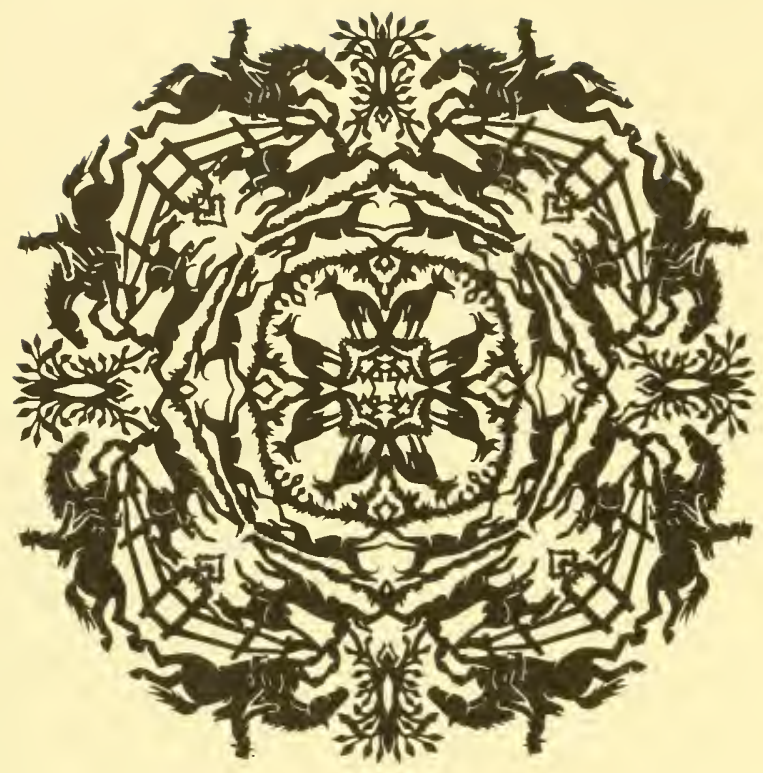

\section{JOHN A.SEAVERNS}

Webster Family Library of Veterinary Medicine Cummings School of Veterinary Medicine at Tufts University 200 Westboro Road North Grafton, MA 01536 


\title{
OBSERVATIONS
}

\author{
ON THE
}

CAUSES WHICH CONSTITUTE

\section{UNSOUNDNESS IN HORSES.

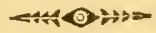

- PRICE FIVE SHILLINGS. 
If not the lowiduig ah liciturfoes Shickesi hone than kef the beveniefs?

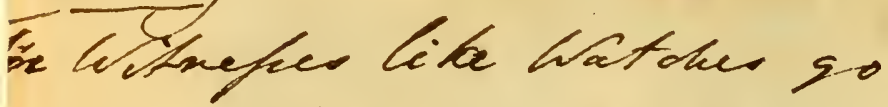
'art ar they .e oct to far a ola w

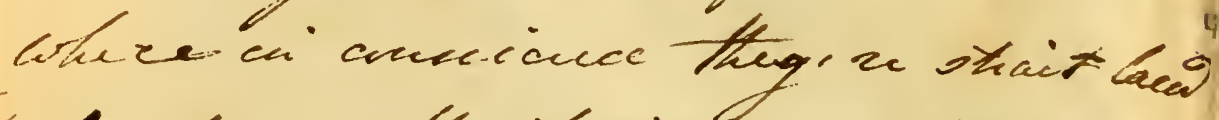
ter to me that side is car to.'

Butter 


\section{OBSERVATIONS}

ON THE

CAUSES WHICH CONSTITUTE

\section{UNSOUNDNESS IN HORSES,}

CONSIDERED

IN REGARD TO THE SALE AND PURCHASE

OF TIIOSE ANIMALS.

DEDICATED TO THE GENTLEMEN

OF THE

Cuglisil ziar.

"Equo ne credite, Teucri." VIrG.

$\longrightarrow 031000$

\section{By RICHARD LAWRENCE, VETERINARY SURGEON,}

Fellow of the Birmingham Philosophical Society, and Author of An Inquiry into the Structure and Animal Economy of the Horse.

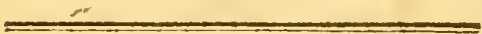

\section{BIRMINGIAMI:}

PRINTED BY R. JABET, HERALD OFFICE, HIGH STREET,

And sold by B. Crosby and Co. Ludgate Hill, London;

J. P. Lucas, 10, High Street, Birmingham; and all other Bcoksellers. 


$$
\begin{aligned}
& \text { Saverns } \\
& \text { SF } \\
& 959 \\
& 125 \\
& 139 \\
& 1809
\end{aligned}
$$

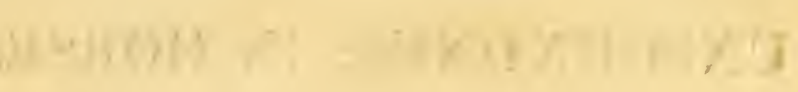




\section{DEDICATION.}

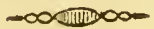

TO THE

\section{Gentlemen af the englíf ฌar.}

GENTLEMEN,

I SHoulo be greatly deficient in gratitude, if I did not avail myself of this opportunity of publicly acknowledging the agreeable ordeals I have, at various times, gone through in your formidable and august presence.

As none of you, Gentlemen, are endowed with the faculty of taking an introspective view of your own craniums, it cannot be expected that you should entertain any precise ideas of unsoundness in the animal weconomy; I have, therefore, presumed to 
imagine that the following Essay will, in many respects, be found useful.

When called upon to exercise your abilities in a horse cause, and when the respective properties of the subject that may happen to be in dispute, are taken into consideration, the jury can seldom be at a loss for cxamples to direct thcir judgment.

In the qualities of grace and dignity of action, many of you exhibit a striking analogy to that noble animal; and although the professional peruque is not strictly the fac simile of the flowing mane, yet the lofty carriage of the head, the grand expression of the eye, together with the tremendous accompaniement of thumping the table, must ever remind them of that sublimity of motion which Virgil (speaking of the horse) has thus poetically. described, "Gressus glomerare superbos." And who can witness the accustomed preparation for the exordium, withont calling to mind the following passage in Dryden :-

“ 'Th' impatient courser pants in every vein, And, pawing, seems to beat the distant plain; Ilills, vales, and floods appear already crost, And ere he starts, a thousand steps are lost."

But perhaps the following parody may not be macceptable:- 
Th' impatient counsel pants in every vein,

Looks round the court, then smirks, and lopoks again; Judge, jury, all, appear already crost, And ere he starts, th' opponent's cause is lost.*

With regard to the diseases of the horse, especially that which is denominated roaring, juries must be deaf indeed if they are not satisfied with the illustrative specimens which many of you display in the progress of your orations; the disease, indeed, which is known. by the term short winded, and the unpleasant defect of shyness, I must confess are not so well exemplified, having never heard any of you accused of either of those imperfections. In the article of restiveness, some comparative observations may certainly be made, it being no unusual circumstance for

* In case the foregoing description of the preparation for the contest should not be deemed sunficiently energetic, the following passage from Ovid, describing the fury of the boar, antecedently to the combat, may be introducer with propriety and effect :-

"Fuimen ab ore venit, frondes afflatibus ardent."

Which may be thus freely translated :-

Lightuing issucth from his mouth, and the briefs are set on fire by his breath.

In selecting the above quotation, I have no wish to comparc the learned tribe to boars, although the fashionable appellation of bore has frequently been applied to some of these clesul. sorious orators, 
some of you to move sideways, when you ought to go straight forwards, and the kicking and wincing which occasionally occur among the members of your learned body, sufficiently characterise those agreeable accomplishments in the horse, without the necessity of farther demonstration.

But, beginning to feel as if I was actually in court, it behoves me to reflect, that the following performance may be subjected to a cross examination; and who shall abide the introductory " hem," the re-adjustment of the wig, or the preparatory blowing of the nose, signals of attack which even his Ludship on the Bench can rarely contemplate without emotion and alarm.

It would ill become me, Gentlemen, who have received so many civilities at your hands, to condemn the casual aberrations of fancy into which you are sometimes betrayed by genius, or the freedom of remark which generally embellishes your orations. Certain splenetic and unpolished members of society, insensible to that sucity of mamners which usually adorns your inquisitorial labours, may, perhaps, object to those little indulgences usurped by your profession, and may feel disposed to dispute the title upon 
which you exercise the privilege of circumlocution in your questions, while you confine the poor witness to the bare response of "Yes or No."

The court is, indeed, sometimes so unmindful of decorum as to laugh at an unexpected retort thrust in " $\mathrm{Vi}$ et armis," and in defiance of the fortifications in which you are intrenched. Thanks to a just sense of propriety, I have never so far forgotten myself as to join in any such irreverent exultation. The gravity and dread dignity attached to your Paraphernalia, have ever protected you in my consideration against such irruptions of coarse jocularity.

Some, perhaps, will accuse me of having flatered you in the foregoing observations, and may suspect that I am a candidate for the honour of being admitted to your conrivial parties, and of joining you in your first and favourite toast, "the glorious uncertainty of the law." B But I spurn such

* The custom of drinking torsts is of great antiquity. The Romans usually drank nine cups to the Muses, and three to the Graces; whence arose these verses of Ausonius :

"Ter bibe, vel toties termos sic mystica Lex est,

"Vel tria potanti, vel tria multiplicanti."

As the Muses and the Graces so eridently diride their favours among the Members of the Long Robe, that it is dificult to 
illiberal imputations, and enjoying, in its fullest extent, the "Mens conscia recti," I "defy any man to convict me of ever having. held a candle to the devil.

With the most profound admiration of your argumentative dexterity,

I remain, GENTIEMEN,

Your most obedient servant,

\section{RICHARD LAWRENCE.}

decide to which they are most indebted; it may be presumed that the learned fraternity do not strictly adhere to the above rule, but quaff an equal number of bumpers to each. 


\section{PREFACE.}

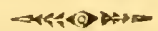

"EQUO ne creditc, Teucri." Fastidious critics will, perhaps, deem the above quotation too remote to be applied to the subject of the present 'Treatise. Admitting, however, that it was a wooden horse of which the Trojans were bidden to beware, still there are many, in these later times, who have had the misfortune to purchase aooden horses, and who have had ample cause to lament the want of a prophetic admonition against receiving them, not into the capital, but to a place of infinitely more importance to some of our modem 'Trojans, the stable.

Virgil, it is true, has not specified whether the Grecian horse was nick'd or cropt, or whether he was figg'd in the present scientific manner, at the time he was exhibited before the walls of 'Troy. To our classical 
Readers such minutic as these may appear unimportant, but there are a certain description of Literati at Tattersall's and Aldridge's, as well as in the Barouche Club, lately established, to whom such a circunstantial account would, no doubt, be peculiarly satisfactory and interesting.

The Grecian horse, we believe, was warranted sound, and free from vice, and it seems that the Grceks were as well versed in that species of recommendatory panegyric as any of our modern dealers, a great similitude appearing between the issue of that transaction, and most of the bargains of the present day.*

Persuaded, therefore, that the foregoing observations will sufficiently justify the adoption of the motto, I shall now attempt to give a generic description of the horsedealers of modern times, some of whom have been denominated Greel's, doubtless in commemoration of their Grecian predecessors.

The Reader will be disappointed if he expect to find, in the following pages, a

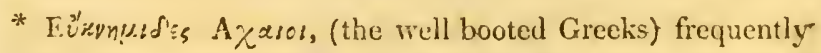
occurs in Homer; whether any of them were horse dealers, I shall leave to the Editor of the "Censura Literaria" to determine. 
furious philippic against that ingenious body of men. Such an attack would be dangerous in the extreme, not only on account of the number, but also the rank of the parties, as it is a well known fact, that this respectable profession is not confined to that branch who attend the public fairs, and take out licences, for many of our Nobility and Gentry manifest a laudable ambition to rival its members in the exercise of its peculiar mysteries.

'There is this distinction, however, between the common and the gentleman dealer, viz. that the former is obliged to warfant a horse sound before he can sell him, whereas the latter simply avers, that he believes the horse to be sound, but that it is not his custom to give a warranty. 'Thus the first is bound by law, the latter by honour ; nevertheless, there are some eccentric and narrowminded purchasers, who, in spitc of the numerous bright examples of modern honour, prefer the former mode of dealing to the latter; but, far be it from me to assert, that they are thereby more secure. The law, indeed, takes cognizance of deceptive practices in this branch of traffic, as well as of any other; the difficulty of putting it 
into force arises from the rersatile and undefined doctrines maintained at different periods on the same subject.

An attempt to methodise those doctrines, and to bring them to some certain standard, may, perhaps, be decmed presumptuous by those who are unacquainted with the opportunities I have reluctantly enjoyed of becoming experienced in disputes of this nature.

My object, I wish it clearly to be understood, is not (according to the common phrase) to lay down the law. Such an undertaking would be incompatible with my pursuits, and abore my ability. I wish clearly to confine myself to an explanation of the causes of unsoundness, learing it to the Courts to argue and decide thereon.

Those, who have been accustomed to attend horse causes, well know that there are scaredy two circuits where the same opinions respecting unsoundness are entertained by the respective judges and counsel. 'This clissimilarity of opinion arises more from the obscurity of the subject, than from any desire on their part to new-model the statutes, and, until some certain and unvarying data shall be unisersally acknowledged in the 
Courts of Law, this perpetual fluctuation must continue to take place.

The late Lord Mansfield maintained, that ten pounds was a price sufficient to constitute a warranty, and for many years that principle was acted upon. It lias since, however, been exploded, and the price, at present, is of no effect, except it be accompanied with a written warranty, or a verbal one, delivered in the presence of a third person.

By some judges, the disease called rumning thrushes has been deemed an unsoundness, while others have held a contrary opinion. But Jurlges and Barristers cannot be cxpected to be thoroughly versed in the particulars of a trade, which, even the study of a whole life, exclusively directed thereto, is not always sufficient to acquire. It is the fashion to declaim against the dishonesty of dealers; I am not ambitious of being considered their champion, but, justice obliges me to declare that they labour under many disadrantages, to which no other traders are exposed. If a dealer bring a cause into court, the bias in the minds of the jury is almost invariably against him. He has also generally less evidence to produce on the 
occasion, from the circumstance of the horse having, perhaps, been but a short time in his possession.

When it is considered that, owing to the foolish practice of working horses before they have arrived at maturity, there are very few that are perfectly sound at six years of age, it cannot be a matter of surprise that a dealer, who is obliged to keep up a certain stock, should be liable to be cheated in his purchases, as well as the rest of the community. The dealer buys a horse, of whose secret defects he must in most cases be ignorant, and sells him as soon as he can find a purchaser, He, therefore, is morally less responsible for the defects of the animal, than an indifferent person who sells and warrants as sound a horse that has been in his possession a year or two, and with whose faults he cannot help being acquainted; yet the latter shall not only escape censure, but shall frequently come off victorious in a law suit, by bringing a host of witnesses, such as the colt-breaker and blacksmith, and a few kind neighbours, who think it is but doing as they would be done by, to stretch their consciences a little in support of a friend. Seryants, also, very improperly con- 
ceive, that it is their duty to swear any thing to promote the interests of their masters; hence, the perjury that generally attends a horse cause is shocking in the extreme.

Witnesses, in causes of this nature, however, console themselves by the consideration that they swear only to the best of their judgment. 'This may really be the case with some who are unhackneyed in the tricks of horse-dealing; but the majority, I conceive, will find it difficult to cheat the devil by a salvo of this description.

The shifts and evasions to escape detection in the sale of an unsound horse, are almost innumerable. 'I'hus, if the animal have narrow contracted fect, or if his knces bend over from hard work, the purchaser is gravely told that the horse inherited those properties either from the sire or dam.Again, it is usual with dealers to talk about natural lameness, and they frequently ascribe imperfect motion to that cause. But I could never discover what was meant by this natural lameness. If a colt be foaled with one leg shorter or longer than the rest, consequently his action will be irregular and incomplete; or if he be foaled 
with an imperfect joint, of course, the same effect will ensue. It is a curious fact, however, that there are fewer distorted productions amongst horses than amongst any other description of quadrupeds. In horned cattle and sheep these lusus nature are by no means unfrequent; but, during the whole - of my professional practice, I never saw but one case of the kind, which was a colt sent to the Veterinary College, for the purpose of having two supernumerary feet amputated from the fore legs. These feet, which grew out of the fetlock joints, in the manner of dew claws, were taken off, and the animal afterwards became useful.

Before any positive or correct standard of soundness can be established, it will be. necessary to draw the line somewhere.'Thus, if the strict signification of the term be attended to, a horse must either be sound or unsound. There can be no modification, nor should any attempt to qualify an imperfection be admitted, provided the position I have just laid down be adhered to. But if this were to become the invariable standard, horses must either be much depreciated in ralue, or very few be sold as sound ones; sinec it is a well-linown fact that very few 
attain the age of six years, the period of maturity, without being injured or blemished in some part of their frames. 'The question therefore arises, whether any cxisting defect or blemish, which has a tendency to produce lameness or unsoundness (although that unsoundness has not yet taken place), shall be considered as making the horse unsound at the time of sale. It may be argued that the purchaser buys the animal with his eyes open, and, therefore, has no right to make objections subsequently to the purchase. Such an argument may apply to those who are well skilled in the. trade; but when it is considered how few there are who understand those matters, some rule should be established for the protection of the ignorant against the arts of the designing.

In forming an opinion of the soundness of a horse, it will be necessary to refer to the original principles of his animal econony. Thus, it will be necessary to recollect that the natural shape of the hoof of a colt is circular, and that his legs are free from swellings or exuberances about the joints. Yet a horse may have lost the circular form of the hoof by bad shocing, and other circum-. 
stances, and yet not be positively lame, although his motion may, thereby, be less firm and clastic. The joints may also be puffed with windgalls, and yet the horse shall not betray signs of lameness. On the other hand, cases often occur where lameness is produced from both the above causes, and yet if all horses with narrow feet and puffed joints were to be rejected as unsound, threefourths of the produce of the kingdom would come under that denomination.

It would certainly be unreasonable to estimate the standard of soundness by the standard of perfection, for a horse may be perfeetly sound, and yet a bad mover, and liable to stumble. Also, by having a less capacious chest, and smaller lungs, he may not be so good-winded as another, yet this circumstance cammot constitute unsoundness. 'I'he eyes also vary considerably in their natural formation, some being smaller than others. Horses with small eyes are generally shy and startlish, firom being nearsighted, on account of the Hatness of the cornea or outward surface of the eye: still no disease may exist in the eye at the time of sale, although eyes of this description are justly considered as more liable to blind. 
ness. Dealers distinguish them by the term buck-eyed, or moon-eyed, and generally deem them unsound. But it would be just as reasonable to deem a horse unsound, because, in his natural formation, he might happen to be what is called over-hock'd; a form which, by experience, is well known to be more subject to spavins and thorough pins than any other.

Running thiushes, or rotten frogs, are considered by some as a mark of unsoundness, whilst the contrary opinion is held by others; yet, both a well-formed foot, and a bad-formed foot, may be affected with running thrushes; nor is lameness always a consequence of this discase.

A cough is frequently the forerunner of what is termed broken wind, yet a horse may cough, occasionally, for several years, and not ultimately become unsound in his wind.

Splents, spavins, and curbs, are causes of lameness, yet a horse may be affected with any of these excrescences, without being lame; that is to say, the disease may remain inactive for a certain period, and not be brought into action, except by peculial" circumstances. 
The necessity, therefore, of drawing the line is evident, for the purpose of determining whether the existence (at the time of sale) of any defect likely to produce disease, shall or shall not be considered as unsoundness. But whilst the above-mentioned varieties in the scale of soundness continue to occur, it will be fruitless to attempt to reduce the standard to the positive absence of all blemish or defect; for, as I have before stated, such a measure would exclude three-fourths of the horses in the kingdom.

'Taking the subject in every point of view, there seems to be no other alternative than that of determining, that, if the horse, notwithstanding he exhibit any of the defects or blemishes above mentioned, shall be free from lameness, blindness, or broken wind, at the time of sale, he shall be deemed a sound horse, and not returnable, except disease shall have taken place within a reasonable period. For, the purchaser is supposed to see those defects which are likely to prociuce unsoundness, at the time he makes the purchase, and if he be not a competent judge of those matters, he possesses the means of availing himself of the judgment of professional men, by making application to 
them for that purpose. The reduction in the price also, in the sale of a blemished horse, is generally equivalent to the subsequent risk. 'This, therefore, furnishes another argument for the establishment of the above principle.

The Reader will understand that this doctrine is intended to provide only for cases where an actual warranty has been given; that being the only ground upon which litigation can be maintained.

In returning a horse as unsound, it has generally been supposed to be necessary that the seller should receive him again to make it a legal return. Hence it has sometimes happened, in the event of a refusal, that the horse has been turned loose on the premises of the seller. 'There is no necessity, however, for this process; it being sufficient to give notice, by a witness, that the horse is not accepted, and that he is ready to be delivered up, when sent for. This point has lately been established in our courts of law; and the justice of it is evident, for there may be a distance of a hundred miles between the parties, and the mortification and disappointment arising from having bought an unsound horse, must 
bear sufficiently hard upon the buyer, without his being exposed to the risk of accidents that might happen to the horse on the road, during his return. 'The proper mode to be adopted in a dispute of this nature, is to send the animal to a neighbouring livery stable, there to remain until the final issue shall take place; and, consequently, at the expence of that party to whose lot he may ultimately fall.

In addition to the above precautions, it is adviseable that the purchaser should neither have the horse newly shod, nor the shoes removed, until a sufficient time has elapsed, from the period of the purchase, for the discorery of lameness. The policy of this measure is obvious, as it gives the seller no. opportunity of attributing the lameness to either of those causes. In case, also, of any bodily unsoundness, the purchaser should be careful not to administer medicine, lest the seller should ascribe the complaint to an injudicious treatment of the animal, after he was out of his hands.

Purchasers of horses are generally desirous to keep the price secret; hence, it seldom happens that a third person is present during the negotiation. On this account, 
great dificulty frequently arises in proving a waranty. Whe same dithiculty oceurs in bartering, or, in the vulgar phrase, chopping one horse for another; it being a received (though an erroncous) opinion, that that mode of trafice remores all responsibility from both parties. A warranty, howerer, is as good and binding in chopping a lorse, as it is in sclling him for money, provided the waranty can be proved. Ilige nost simple and certain mode of obtaining a warranty is, to procure a receipt, on a proper stamp, and in the hand-rriting of the seller, describing the horse, and warranting him sound. 'This is evidence which cannot crs, and which all the ingenuity of the whole legal fraternity together cannot invalidate nor set aside. 'The form of the receipt may jun thus:-

RECEIIED, on the Day of of Mr. A. B. the sim of Fifty Pounds for a bay horse, warranted sound and free fiom vice.

\section{D.}

The adrantage of obtaining a receipt is manifest also in cases of the following de- 
scription. In the purchase of a horse, it sometimes happens that the purchaser expresses his apprehension of the horse becoming unsound, on account of some partial and visible defect. In such a case, it is not uncommon for dealers to offer a special warranty against the consequences of that particular defect, perhaps for six, or eren for twelve months. This, therefore, (in addition to the general warranty), must greatly increase the security of the purchaser; but it should never be left to a verbal assurance -it should always be committed to paper; in which case the receipt may run thus:"for a bay horse warranted sound, and also warranted, for six months, from lameness from the present enlargement in the look joint of the aff fore leg, (supposing the horse to have some blemish in that part); or in case of doubtful eyes, the same mode may be pursued; viz.-and warranted not to gुo blind for six montíns."

* It may, howerer, admit of some doubt, whether a receipt of the description above mentioned might not come under the denomination of an agreement, and, consequently, would not be valid, except on an agreement stamp. But, even in that case, the additional stamp might be affixed, if necessary, at any subsequent period, by sending it to the Stamp Office, and paying the sum required for that purpose. 
It is true that some difficulty may subsequently arise in proving a lameness to have originated in any particular part of the limb; but, when an ostensible cause exists, it surely camnot be unreasonable to attribute it to that cause. With respect to the length of time that ought to be allowed to ascertain the soundness of a horse, or, in other words, the length of time between the delivery and the return, various opinions have been held. At Tattersall's and Aldridge's repositories, in London, I believe, not more than three days are giren, from the time of sale; in other places, a week or fortnight.

It is difficult, however, to decide on the proper period, as much must depend on the distance between the place of sale and the residence of the purchaser, which, of course, must require more or less time for the return, according to circumstances. Sellers of horses are subject to much unfair treatment from grooms and coachmen, if they neglect to present those gentlemen with the accustomed fee, or if the amount does not happen to accord with their expectations. In cases where this ceremony has been omitted, the animal undergoes every species of violence, in order to render him unsound, 


\section{Ixvi}

PREFACE.

or with a view to produce some pretext for returning him. It, therefore, behores masters to look well to the conduct of their servants, or they may become involved in expensive law-suits, and for no other purpose than to gratify the spleen and revenge of those rapacious knaves.

It is sometimes the practice of purchasers to put their new purchases to the test, by galloping, leaping, \&c. to try if they are sound. But, when the numerous accidents, to which the animal must necessarily be exposed during a trial of this description, are taken into consideration, and when it is certain that the soundest horse may, even by the smallest irregular position of the foot, become lame in one moment, perhaps irrecoverably, it cannot be supported, either by reason or justice, that the seller should suffer by such inconsiderate and unfair conduct.

Thus far have I endearoured to elucidate this intricate subject. In the observations which I have offered, my sole object has been to remore vulgar errors and prejudices, and to simplify, if possible, a branch of traffic, of no small importance to the inhabitants of this kingdom. If I have failed in the attempt, if I have left the subject 
in the same obscurity and perplexity in which I found it, let it be remembered, that I am the first who has undertaken the Herculean task, and an therefore entitled, at least, to the approbation of the Public for my good intentions, however they may have fallen short of success.

'I'o reduce the number of horse causes is a matter of some moment to the interests of morality, inasmuch as it must tend to check that system of infamous and shameless perjury, which too often exhibits its daring front in our courts, in trials of this nature.

The witnesses are gencrally of the lowest order in society, consisting, perhaps, of the very dregs of the stable. On men of this description, what impression can be expected from an oath, administered in a negligent and slovenly manner, and gabbled over with such rapidity, that not a single word, except the last, can be distinguished or understood. In adverting to this abuse of a most sacred obligation, I mean not the smallest disrespect to our constituted legislative authorities. The abuse, like many others, may have crept in unperceived; but surely there can be no good reason why the 
administering of an oath should not be attended with the same solemnity, as any other ceremony in a court of justice.

Having thus pointed out the difficulties attending disputes respecting the sale of horses, I cannot do better than to warn my Readers against entering into law-suits on those occasions. The average expences of a suit, are from one hundred and fifty to two hundred pounds, and as it is a rule to tax the costs, and generally to take off a third, of course the payment of this third must fall on the winner, who consequently will be about seventy pounds out of pocket, which is the average price of most horses that are brought under litigation. If the Reader, however, is not satisfied with this advice, let him turn over the pages of $\mathrm{Hu}$ dibras, where he will find the following appropriate quotation -

"He that by injury is griev'd, And goes to law to be reliev'd, Is sillier than a sottish chouse, Who, when a thief.has robb'd his house, Applies himself to cunning men, To help him to his goods again; When all he can expect to gain, Is but to squander more in vair. 


\section{OBSERVATIONS, \&c.}

\section{- बसE(O) \\ CHAPTER I.}

THE Causes which constitute Unsoundness in Horses may be classed generally under the three following heads, viz. Lameness; imperfect siglit, and defective respiration, or diseased state of the lungs. There are, however, two or three other imperfections, which cannot, with propriety, be included in the above series, such as crib-biting, wind-sucking, shivering of nervous agitation, and megrims, or temporary apoplexy. As all these last mentioned defects reduce the value of a horse very considerably, I shall endeavour to explain their nature and consequences in the course of my observations.

But, previously to pointing out the diseased state of the different parts of the animal, it will be necessary to describe their structure and oconomy in the healthy state.

Whoever will give himself the trouble to reflect on the aljuses to which horses are subject, as well as the improper treatment they experience in their domesticated state, will 
not be much surprised that so few of them are perfectly sound. Farmers, in general, ride colts even at two years of age, and the consequences of such premature exertion are sufficiently manifest in the production of bony excrescences on the limbs, such as splents, spavins, ring bones, \&c. As lameness, therefore, is more frequently the cause of unsoundness thàn any other disease, I shall commence with that subject, and shall occasionally introduce quotations from a treatisc on the structure and animal occonomy of the horse, of which I published a sẹcond edition about three years ago.

Lameness may originate from a diseased state of the hoof, or of the muscles; tendons, ligaments, and bones. As the most frequent seat of lameness is in the foot, it will be necessary. to enter into an anatomical cletail of that part of the limb.

The hoof of a colt is nearly circular in its form; it is also concave in the sole; it will therefore be obvious, that the most prominent parts of the sole must come immediately into contact with the ground. These parts are the wall, the binders, and the frog. The heels are naturally capable of an elastic expansion, when the loof is not shod. This elasticity contributes to facilitate the circulation of the blood through the foot, to furnish a spring to the 
action of the leg, and to lessen concussion. Any circumstances, therefore, that deprive the hoof of this property, will consequently produce lameness. The most dangerous enemy the hoof has to encounter, is the Blacksmith; and although the mischief arising from bad shoeing may be slow in its progress, yet it is fatally certain in its effects.

The most ostensible injury produced by bad shoeing is a gradual contraction of the heels. 'This contraction, acting' by compression on the internal parts of the foot, brings on the sensation that a human being would feel from wearing a tight shoe. In this state, the horse does not put his feet to the ground with that resolution and firmness which he would do in a state of nature, and hence arises that short shuffling manner of going, which dealers distinguish by the term "groggy."

When the contraction exists to a great degree a perfect cure is rarely obtained. This conraction, however, never takes place suddenly, as the internal parts of the foot will resist it for a certain length of time, but the continued pressure on the quarters will ultimately produce a partial absorption of the coffin bone, which is obliged, in this manner, to adapt itself to the diminished capacity of the hoof. Feet which are disposed to contract, generally póssess great strength and thickness in the wall or crust. 
The heels, also, by being suffered to grow too high, prevent the frog fiom coming into contact with the ground. Hence the frog becomes soft and rotten, and so extremely tender, that when it presses on a stone, or any other hard substance, the animal experiences great pain on the occasion. The sole of a very strong narrow hoof, is generally preternaturally concare, so that it is forced upwards by the lateral compression of the quarters against the fleshy sole, causing considerable and permanent pain in that part. Corns, also, frequently arise in hoofs of the above description.

The mcans usually employed to effect a cure, are by attempting to expand the heels by artificial means, with a view to relieve the internal parts of the hoof from that painful compression which produces lameness. But the restoration of the original form of the hoof does not always produce a remetly; for, in some cases of the above description, the cartilages or gristly parts of the coffin bone become so completely disorganized as to lose their functions and elasticity. This, therefore, sufficiently demonstrates the risk incurred in buying a horse with narrow or contracted heels.

The above diseases arise from too much strength and thickness in the walls or crust of the hoof, and they are considerably accelerated 
in their progress by bad shoeing; and the heat and dryness of the stable.

Other diseases, howerer, are produced in the foot, from a direct opposite cause; nanely, weakness in the walls or crust. In this case the sole sinks to the ground, and instead of being in some degree concave, it is frequently convex, so that the middle of the sole touches the ground before any other part of the hoof. This is called a pumied foot, and a horse with a hoof of this description, cannot travel with case or safety, except the sole be raised from the ground by a broad convex shoc. The heels of a pumied foot are so weak, that their natural growth is not sufficient to resist the weight of the body; hence they are never so high and prominent as the sole and frog, and never require to be pared with the buttress in shocing. The frog, however, by the pressure which it is obliged to endure, is always sound, and hard; consequently, horses with feet of this form very seldom have rumning thrushes, though they are liable to corns and bruises in the sole, from its being more exposed to injury. Horses, nevertheless, may be subject to both the above cases of malformation in the feet, and yet not be absolutely lame. Those defects, therefore, do not always constitute unsoundress, except the animal be lame at the time of sale. 


\section{RUNNING THRUSHES}

Constitute a very troublesome disease, if they are suffered to increase. There are few horses that are not more or less subject to them. Even colts at grass are sometimes affected by them, under certain circumstances, such as the height of the heels, arising from their not being sufficiently worn down so as to bring the frog: into contact with the ground, also by running: in soft and wet pastures. At the same time it must be admitted, that horses of a hot temperament have a predisposition to this clisease ; and it is probable, that the discharge may, in some measure, prevent other discases in the limbs. Hence it has been considered dangerous to dry up the frogs; and indeed it sometimes occurs, that a sulden suspension of the discharge, by the application of astringents, wilk produce immediate lameness, from a subsequent inflammation taking place in the foot. The disease, however, may be progressively palliated, and even totally removed; and where it occurs, independently of any other inperfection in the form of the hoof; it cannot with propriety be considered as rendering the animal unsound. On the other hand, where it accompanies a contracted foot, it is generally the consequence' of the contraction, and therefore tends to con- 


\section{5}

firm the unsoundness produced by that contraction.

A rumning thrush, if long neglected, will sometimes terminate in a canker, destroying. the laminated fibres between the outward surfice of the foot, and the inward surface of the hoof. When the disease has arrived at this height, the cure is both tedious and difficalt, and frequently a considerable part of the walls of the hoof are obliged to be cut away: There can be no hesitation, therefore, in deciding that a canker in the hoof constitutes unsoundness.

\section{CORNS}

Arise in the heels of the hoof, gencrally on the inside quarter. They are discovered by a partial redness and softness in that part of the heel. They are very troublesome, and are seldom radically cured. Horses, with hot and dry feet, are most subject to them, and they are generally brought on by bad shoeing. If the shoe be too short in the heel, or if it remain on the foot so long that the heel of the hoof grows over it, the partial pressure will bruise the heel, and produce a corn. This disease makes the horse very tender-footed, and liable to stumble when he treads on a hard projecting: substance; hence, it is eustomary to shoe the animal with bar-shoes, so that the heels and 
frog are completely corered. But the remedy is worse than the disease, for, after a certain length of time, the hecls acquire the shape of the shoe, and become so convex that the animal is unable to travel with a shoe of any other description. A corn is sometimes attended with so much inflammation that suppuration will take place, and an ulcer break out on the coronet, above the hoof. If a horse be affected with only one corn at the time of sale, and his hoof, in all other respects, be sound and well-formed, it is probable that the disease may arise, in that case, from a bruise, and the mischief be only temporary. But if the animal have corns in both heels of the same foot, or in one heel of both feet, it is pretty certain that they arise from a diseased state of the feet, and, undęr such circumstances, there cann be no doubt that the animal is unsound.

\section{SAND-CRACK}

Is so called from its causing a crack or fissure in the quarter of the hoof, from the coronet lownwards. It commonly arises from dryness in that part which lies between the hair and hoof. Sand, or other earthy particles, getting into the crack, bring on inflammation and lameness, which is seldom removed until the fissure is laid open, and proper dressings are applied. 
The hoof, however, cannot be said to be perfectly sound until the crack is completely grown out; and as this process goes on from the coronet downwards, it frequently requires five or six months before this object is effected. Whoever, therefore, purchases a horse with a sand-crack, may generally calculate on his being of no use to him for the space of time above-mentioned. The disease is also liable to return, if the coronet be injured or dividerl. On this account, a horse with a sand-crack must be considerably reduced in value, even if he be considered as sound at the time of sale. Previously to purchasing a horse, it is necessary to examine the quarters of the hoof, as a sandcrack may be concealed by covering it with pitch, and colouring the surface in imitation of the hoof.

\section{A FALSE QUAR'TER}

Is an irregularity in the surfice of the wall of the hoof, occasioned by one part of it projecting beyond another, in a perpendicular direction; namely, from the top to the bottom. It is produced hy some injury done to the coronet, from whence the hoof issues. Excepting its being somewhat unseemly, it is of little consequence, and seldom renders the horse lame. 


\section{LAMENESS IN THE COFFIN JOINT.}

This generally arises from a strain of the ligaments, which hold the foot or coffin bone, and the lesser pastern bone together. This joint is seated within the hoof, and is much cxposed to injury from any sudden shock, or irregular position of the foot. If the disease continues to exist for a considerable length of time, an anchylosis, or complete union of the two bones, will take place. In this case the joint is irrecoverably lost; and although the horse may feel no pain in the part affected, yet his motion will be imperfect, and the pastern being less flexible and elastic than in its natural state, that part of the limb will appear stiff and upright.

Lameness in the coffin joint is not discoverable by any external swelling; hence it generally happens that the lameness is attributed to some injury in the shoukder; and during the period that the remedy is applied to that part, the disease is going on in the foot, and for want of timely relief becomes incurable. It is almost unirersally accompanied by a contraction of the hoof.' This is brought on by the horse holding out the lame leg before him, and not pressing on the houf. Hence, if a horse 
have one hoof more contracted than the other, it gives just cause for suspicion, that the horse has been lame in the coffin joint at some former period.

At the same time it will be proper to state, that a contracted hoof may sometimes arise from the foot not being equally pressed upon, in consequence of lameness in any other part of the leg.

If, therefore, a horse have one hoof more contracted than the other, and if the pastern of that leg be more upright and less pliable than the other, he certainly cannot be deemed a sound horse.

\section{OSSIFICATION of the CARTILAGES of the FOOT.}

Or each side of the hoof, just above the coronet, are two cartilaginous or gristly substances, issuing from the upper edge of the coffin bone. These cartilages are elastic in their healthy state. They lie immediately over the large blood vessels which run into the foot, and furnish a defence to them from external injury; they contribute also to the elastic expansion of the heels. From some cause, not thoroughly understood, they sometimes become ossified, or converted into bone. This change 
in their organization may be easily ascertained, by pressing that part of the coronet with the hand. If sound and healthy, they will yield to the pressure; but, if converted into bone, they will feel hard and inelastic. In this latter state, they generally occasion lameness, or, at least, an imperfect motion; and certainly, under those circumstances, a horse camnot be considered as sound.

\section{LAMENESS IN THE LEG.}

THE bones of the leg are frequently diseased by ossifications, or bony excrescences, arrsing in different parts of the limb. These ossifications are distinguished by various names, according to the situation of the part affected, viz.

SPLENT;

RING BONE,
BONE SPAVIN:

The most common of these is the Splent; and indeed there are few horses without them, at some part of their existence. As a Splent, however, often occasions lameness, it will be necessary to point out under what circunıstances it may be considered as indicative of unsoundness.

Splents generally arise on the inside of the shank bone, between the knce and the fetlock 
joint. They are produced by partial inflammation in the bone, from concussion upon hard roads, or by blows from the opposite leg during progression. This last defect is called the speedy cut.

Young horses are more subject to splents, their bones not having acquired that firmness, which takes place in a more alvanced age. The disease is more or less important, according to its situation. 'Thus, if the splent arise on that part of the bone which is unconnected with any ligament or tendon, the lameness is seldom of long duration; but if it arise under the ligament, or near a joint, the consequences will be more serious; because the ligament will be forced out of its natural direction, by the partially increased substance of the bone, and the functions of the joint must be interrupted also from nearly the same cause.

The lameness arising from splents generally takes place during the first period of their formation. Hence it frequently occurs, that the animal will be lame for some time previous to the enlargement of the bone. The periosteum, or thin membrane, which surrounds the bone, being distended by the increased size of the part underneath it, becomes highly irritable and sensible of pain, when the limb is jarred by the concussion which it experiences when 
the foot alights on the ground. The periosteum, however, soon adapts itself to the enlargement of the bone, and the lameness will then disappear, provided the splent is not seated under a ligament, or a tendon; for, in that case, the lameness is generally more durable, and more liable to return. If, therefore, a horse be lame, at the time of sale, from a splent situated immediately under a ligament or tendon, it cannot be unfair to deem him unsound, because the complaint seldom admits of a permanent cure. On the other hand, if the splent appear only on that part of the bone, which has nothing over it but the skin, it ought not to reduce a horse in value, because the disease may be easily removed; and incleed instances are by no means uncommon, of splents being absorbed by the spontancous efforts of nature.

\section{RING BONE}

Is an ossification, or bony enlargement, just above and mostly in front of the coronet of the hoof. Its consequences are an anchylosis, or union of the lower pastern joint, thereby depriving it of the power of flexion, or, in other words, producing a stiff joint. When the disease has arrived at this state, it is perfectly incurable; and it may justly be considered as 
one of the worst species of lameness with which the animal can be aftlicted. It is, however, of less importance in a hind leg than in a fore leg, and this arises from the obliquity with which the hind leg alights on the ground, so that less flexion and elasticity are required in the lesser pastern joint of the hind leg, than in the fore leg.

\section{BONE SPAVIN}

Takes place on the upper end of the bone of the hind leg, adjoining the lower and inside part of the Hough, where it forms a round bony excrescence.

The hough is more frequently the seat of lameness than any other part of the hind leg. Young horses, whose houghs stand obliquely, a form which is commonly termed cow-houghed, are particularly subject to this complaint. The lower part of the joint of the hough is composed of several small bones, which, though they are exactly fitted to each other, and occupy one common cavity, yet possess a distinct separate motion, independent of each other.

The utility of this conformation consists in furnishing greater elasticity to the joint than it would have possessed, had it been composed 
of one solid mass. When the inflammatory attack commences in this part, bony matter is throw'n out, and an union of these small bones ensues, forming together a hard substance, perceptible not only to the touch, but to the eyc. When an union of these bones has taken place, their original individual motion and clasticity will be lost, and the result will be an incurable lameness. The lameness, however, generally begins before the sparin makes its appearance, and then is the proper period for attempting a cure, by preventing its formation by blistering or firing.

On the first attack of a spavin the horse steps short with the lane leg, and does not bend his hough so much as in the healthy state. The lameness, sometimes, goes off as soon as the animal becomes warm by having gone a mile or two; but it returns as soon as he has rested for a small length of time. Hence it is more adviseable for the purchaser of a horse to see him when first led out of the stab?e, in which case the lameness will be sufficiently manifest.

Instances sometimes occur where horses have been lame, at different periods, for sereral months prior to the formation of a sparin. In such cases the lameness is commonly attributed to some disease in the stifle, or in the 


\section{5}

whirl bone joint, and the mistake is unfortunately seldom discovered until the sparin is confirmed beyond the power of removal. Nevertheless, lameness does not always attend the existence of a spavin, and in those instances 110 defect is perceptible, except a trifling stiffness in the joint, not to be detected except by very close observation.

In some horses the lateral projections of the hough joint are naturally larger and more prominent than in others. An appearance of this kind should be distinguished from a spavin, and this may be ascertained by observing whether both hocks are alike, in which case the projection arises from the natural growth of the part, and not from disease. Natural projections of this description, however, are never confined to the hough joint only, for the same bold and firm articulation may be perceived in all the other joints of the same animal.

$\Lambda$ bone sparin most generally takes place on the inside of the hock, but it sometimes occurs on the outside, and is equally productive of lameness.

The foregoing causes of lameness arise from diseases in the bones. Other causes, however, of lameness are to be found in the ligamentary or tendinous parts of the limb.

These may be comprised under the following heads, zis. 
STRAINS OF THE SIIEATH OF THE TENDONS, RUPTURE OF THE SUSPENSOR LIGAMENTS OF THE LEG, THOROUGH PINS, BLOOD SPAVINS, BOG SPAVINS,

CURBS, WINDGALIS,

INJURY IN TIEE WIIIRL BONE, INJURY IN TIE STIFLE, INJURY IN THE SHOULDER.

The first of these will, perhaps, be better understood by the common term of strain in the back sinews, which generally shows itself on the back part of the leg, between the knee and the fetlock.

It may be brought on by sudilen and violent exertion, or by a blow from the toe of the hind foot, which accident often occurs in hunting over heary land, in which case the fore leg. is prevented from extricating itself in time to aroid the toe of the hind leg.

The injury very rarely exists in the tendon itself, but is more generally confined to the sheath which surrounds it. In the early stage of the complaint the strain may be relieved by spirituous applications and bandages, so as not to become a permanent cause of unsound- 
ness. But if it be improperly treated, the swelling will never subside, nor will the sheath recorer its proper strength and tone, in which case the lameness will perpetually recur after a hard day's labour. Under these circumstances a horse camnot be considered as sound; for although he may be patched up for a short time, yet no dependence can be placed upon him; hence he must be considerably reduced in value.

\section{RUPTURE OF TITE SUSPENSOR LIGAMEN'S OF THE LEG, com- monly called BREAKING DOWN OF IHE BACK SINHWS.}

This complaint is erroneously supposed to exist in the tendons. This, however, is not the fact. The injury takes place in the ligaments which connect one part of the limb with the other. When this disease occurs, the pastern joint drops much lower towards the ground than it does in its natural state; and although the muscles and tendons still retain their power of acting, yet they will act to a considerable disadvantage, on account of the pastem having lost its proper position, as well as being deprived of its chief support.

In this state, blistering and firing are generally had recourse to, but with little effect. 


\section{8}

A horse, therefore, labouring under this complaint, cannot be considered as sound.

\section{THOROUGH PINS}

Consist of a swelling and relaxation in the liganentary part of the hough. They are manifested by small puffy swellings, about the size of a wahut, both on the inside and outside of the hough. When pressed, the swelling yields to the fingers, but returns again as soon as the pressure is removed. It seldom occasions lameness, except it be accompanied with inflammation. It is, however, a pretty certain indication of the horse having been hard worked.

\section{WINDGALLS}

Are of the same nature as thoroughpins, with this difference, that they are seated on the pastern joint, instead of the hough.

They occasion lameness when in an infamed state, but in other respects cannot be deemed a cause of unsoundness, since there are very few horses at six years of age without them. They are brought on by labour, and are probably rendered much worse by the horse being obliged to stand up hill in the stall of the stable; in 


\section{9}

which case the ligaments of the joint are perpetually on the stretch, and, consequently, much injured.

\section{BLOOD SPAVIN.}

This disorder consists of a relaxed state of that part of the vein which passes over the front of the hough. It very rarely occurs, and it is very doubtful if it ever produces lameness; but it is often confounded with another disease, called the

\section{BOG SPAVIN,}

Which consists of an inflammation and distension of Bursa Mucosa, or the parts surrounding the ligament of the hough. In this state, the vein which lies immediately over it is forced forward; and lience the disease has, erroneousty, been supposed to lie in the rein. The Bog Sparin is a disease of great consequence, as it reduces the strength of the horse, and is very tarely cured.

\section{THE CURP}

Is manifested by a swelling on the back part of the hough, and consists of a strain in the annular ligament, which holds the tendons in 


\section{0}

their proper situations. This complaint prevails chiefly among young horses, particularly those which are cow-houghed, or whose houghs describe an acute angle with the thigh. $\Lambda$ curb will occasion lameness cluring its inflammatory state, but it is easily removed by blistering or firing. During its inactive state the horse experiences no inconvenience; it is, therefore, doubtful, whether a curb, under such circumstances, should constitute unsoundness, any more than windgalls or thorough pins.

\section{LAMENESS IN THE STIFLE}

Seldom occurs, except from external injury; in which case it is sufficiently apparent by the swelling of the surrounding parts. If, therefore, no swelling exists in the stifle, it is pretty certain that the animal is not lame in that part.

\section{LAMENESS IN TIIE WHIRL BONE, Or the Articulation of the Thigh Bone atith the Pelicis.}

This complaint also very rarely occurs, the joint being surrounded by such massy and powerful muscles, as to be protected, in a great degree, from injury. When the animal is 
lame in this part, he generally drags the leg after him on the toe, and the motion of the hind quarter is so distinct from that occasioned by lameness in any other part, that there can be no difficulty in detecting it.

\section{LAMENESS IN 'THE SHOULDER}

Arises from a blow or from a sudden and violent extension of the leg in passing over a slippery surface. It is distinguished from lameness in any other part of the limb, by the animal moving the leg. with a stiff knee, and in a circular direction outwards. The lameness is seldom of long duration, and is of much less consequence than lameness in any part of the foot. It is, however, a very favourite maxim with country farriers and grooms to ascribe most lamenesses in the fore $\operatorname{limb}$ to some disease in the shoulder, and it has been erroneously supposed that lameness in the shoulder is, nine times out of ten, incurable. In the course of my practice, however, I have known several cases of shoulder lameness, where the animal had apparently lost the use of the quarter, removed in a fortnight or three weeks.

One of the chief causes why lameness, in any other part, is so frequently attributed to the shoulder, arises from the erident wasting 
or diminution of the muscles, during lameness in the fore quarter. But this wasting of the muscles does not take place more particularly from the lameness being in the shoulder, than it does from its being seated in any other part of the limb. The wasting of the muscles arises from the imperfect motion of the limb; and this imperfect action may be produced, as well from laneness in the foot, as from lameness in any other part; for, as soon as the lameness is removed, the limb recovers its perfect motion, and the muscles, consequently, regain theis original size and vigour.

\section{STRING-IIALT}

Consists in a sudden and extraordinary flexion or snatching up of one of the hind legs, sometimes of both. It is difficult to ascertain the cause of this complaint; but, as it renders the action of a horse unseemly, as well as retards his speed, there can be no doubt of its rendering lim unsound. 


\section{3}

\section{CHAPTER II.}

ON THF.

\section{CAUSES OF IMPEREECT SIGH'T.}

Diseases of the eye in horses are so frequent as almost to sanction a belief that he is naturally more subject to this infirmity than any other animal. But, if we consider the confinement to which he is subjected in lot and dark stables, the constant costiveness produced by dry food, and the general derangenent of the system by riolent and excessive excrtions, it will not appear extraordinary that blindness so frequently occurs.

In orler to give a proper explanation of the various diseases incident to the eye, it will be necessary to enter into an anatomical description of that organ,

The cye is placed sideways in the head of the horse, as well as in all other aninals who preserve themselres from danger by flight. 
This position of the eye enables him, in some degree, to see behind him, and to kick against an adversary with greater certainty.

The pupil, or sight (as it is commonly called), is of a circular form in the human eye, but in the horse it is oblong. This form is peculiar to all grazing animals, and gives them the advantage of secing objects horizontally to a much greater extent than is the case with the human being:

The horse's eye, also, in common with that of other grazing animals, has an aclditional muscle seated immediately behind it. This muscle is adapted for the purpose of retracting the eye within the orbit, to shield it from injury, as well as to suspend it in the action of grazing.

The horse's eye differs also from the human in being provided with a thick cartilaginous or gristly membrane, at the anterior corner. This membrane is common to most quadrupeds, as well as to birds. It is known amongst farriers and grooms by the term Hawes, and so unirersally ignorant are they of its use, that they consider it as a disease, and generally remove it by cutting it away. The use of this membrane is to wipe off dust or hay seeds, or any extraneous substance, that may happen to fall on the surface of the eye; the bad consequences 
of cutting it off must, therefore, be sufficiently obvious.

The external surface of the eye, in its healthy state, is thoroughly transparent. The centre of it, which is called the pupil, or sight, is generally of a dark indefinite colour. The pupil has the property of contracting or dilating itself, in proportion to the strength of light which enters the eye.

To examine a horse's eyes with accuracy, he should be led to the stable door, with his head facing the light. In this situation the pupils of both eyes should appear exactly of the same size. As he advances more into the light, the pupils should contract; but if either of them does not contract, the horse is certainly blind of that eye.

This species of blindness arises from a palsy in the optic nerve, and is so little perceptible, that many good judges liave bought horses of this description, without knowing that they were blind of one eye.

Another cause of blindness, more perceptible, but equally incurable, arises fiom an opacity of the chrystalline lens, constituting a cataract; or, to use a more familiar term, a whiteness over the pupil or sight of the eye. This general whiteness over the sight, however, seldom comes on all at once. It commonly begins 
with small gray specks, about the size of a pin's head. 'These snall specks do not interrupt the entrance of light, except in a very trifling degree; but they furnish a certain proof, that the eyes have been diseased at some former period.

Sometines the whiteness is confined to the outward coat of the eyc, and that only over some part of it. In this latter case, the sight is interrupted in those parts only which are covered with the white film. 'This discase is vulgarly supposed to arise from a film or kell growing orer the cye; hence the animal is generally tomented by the application of powdered glass, and other irritating substances, with a view to eat it off, or disperse it. The disease, however, proceeds from the lymph of the blood being forced between the lamina, or coats of the eye, and it camnot be remored, cxcept by absorption.

External discases of the eye are generally attended with inflammation and swelling of the eye-lids, with a considerable watering or running of the tears. These attacks frequently arise from the bites of flies, or other insects, in the summer season, or from hanging down the lead in grazing, or from bites or blows. They are casily remored by bleeding near the part, and by the application of warm water, and 
are never of such dangerous consequences as disease arising from internal inflammation.

In attacks of internal inflammation, a general cloudiness of the eye takes place, but most. frequently without external swelling, or flowing of the tears. The pupil, or sight, is much contracted, even in a dark situation, and the animal becomes shy and startish from seeing objects imperfectly.

This disease comes on independently of external injury, and is seldom thoroughly cured. $A$ horse, therefore, labouring under this defect, cannot be considered as sound.

There is another description of imperfect eyes, known by the name of moon eyes, or buck eycs. This name, probably, originated from some peculiar influence which the Moon was supposed to have upon them, as the inflammatory attacks are generally periodical. In this case the eyes are usually smaller than the common size, and their outward appearance is of a blueish gray colour. The smallness of the eyes, however, ought not alone to be considered as rendering a horse unsound; for at least one-fourth of the horses in the kingdom are formed with naturally small eyes. Except, therefore, they are affected with disease at the time of sale, they ought to be deemed equally sound as horses with larger eyes. Neverthe- 


\section{8}

less, it must be admitted, that small eyes generally render a horse near-sighted and startlish, and are perhaps more subject to disease than others. But though a horse may be less valuable, on account of the natural smallness of his eyes, yet if there be no disease in them at the time of sale, he ought not to be considered as unsound. 


\section{CHAPTER III.}

\section{DEFECTIVE RESPIRATION, OR BROKEN WIND, ROARING, CRIB-BITING, AND WIND- SUCKING.}

THERE is no part of the animal œconomy of more importance than the function of respiration; for no horse can be capable of going fast, for any length of time, except he enjoy a free and healthy action in his lungs. That this useful animal was intended for the purposes of speed is sufficiently manifest by his having a larger chest, and consequently larger lungs, than any other quadruped of the same size.

It behoves, therefore, the purchaser of a horse to be careful in examining the animal; for that state of diseased respiration, which is distinguished by the term, broken wind, has hitherto been found to be incurable. 


\section{0}

There are, however, several slighter degrees of imperfection in breathing, which, though they do not render a horse unfit for labour, yet are generally considered as symptoms of unsoundness. These, in the language of dealers, are distinguished by the terms, high blower, thick winded, \&c. But, as all horses are not alike in the natural quality of their breathing, any more than they are alike in their external form, or in their powers of speed, it would be unjust to deem a horse unsound for not being capable of going upon wind as long as another of a better breed.

The disease which is termed broken wind, is generally brought on by repeated colds, from irregular treatment. It may also be brought on by too great repletion in the blood ressels, by a want of exercise, or by a defective action in the insensible perspiration.

The difficulty of breathing will be greater or less, according to particular circumstances. 'Thus it will always be increased after the animai ins been watered, or after he has filled his stomach with food. At other times the disease is often scarcely perceptible. It may, however, be easily discovered by putting the horse into a brisk pace, especially if it be up hill.

Dealers generally examine the state of a horse's wind, by pincling the npper end of the 


\section{1}

wmdpipe, next the jaw, and thereby obliging: him to cough. If the lungs be healthy, the animal coughs with a loud, full, and clear sound; but if his lungs be affected, he coughs with a short husky noise.

This is, in general, a fair criterion to judge by, although it is not solely to be depended upon in all cases. It is said that certain practices, such as giving the horse sweet oil, or a quantity of shot, will remove the appearance of the clisease for a short time: this fact, however, is very doubtful.

In the healthy state, and during the period of inaction, the animal breathes very slowly, and the motion of his nostrils, ribs, and flanks, is scarcely perceptible. But when brokenwinded, the ribs are scen at every inspiration, and the flank is tucked up and expanded alternately. A short dry cough, of long continuance, is generally considered as the forerumner of broken wind. But this is not always the case, for a horse may cough, occasionally, for a number of years, and yet not become brokenwinded.

In old obstinate coughs, the animal is sometimes relieved by a temporary discharge of mucus from the lungs; and the difficulty of breathing, which always, more or less, attends an accumulation of mucus on that organ, will then totally disappear. It becomes, therefore, 
a question, whether a horse, affected by a cough, under certain circumstances, shall be deemed unsound.

It is a common opinion with farriers and grooms, that the lungs of a broken-winded horse are too large for his chest. This, however, is an absurd notion; for every anatomist well knows, that the lungs of all animals completely fill the chest, as well in the healthy as in the diseased state; leaving no space between their outward surface, and the inward surface of the ribs: thus they dilate and contract, following up, by their own elasticity, the action of the ribs and diaphragn.

The idea before mentioned of the lungs of broken-winded horses being too large for the chest, originated from their comparative appearance, in regard to size, with those of a healthy horse, when examined after death. Thus, if the chest of a lealthy horse be opened when dead, the air of the atmosphere rushes in, and the lungs collapsing, become much smaller than the cavity of the chest; on the contrary, the lungs of broken-winded horses, being thickened by disease, are less elastic, and consequently do not collapse so much as the former; and hence arose the comparative opinion of their being too large for the chest. But the fact is, that, notwithstanding they appear (uncler these circumstances) larger in the dead 


\section{3}

subject, their size, in the liring sulject; is equally the same, whether healthy or diseased; for no vacuum can exist between the lungs and the surfuce of the chest.

No animal can be healthy that does not enjoy free respiration. Hence, the digestive powers of the stomach, being weaker in horses that are broken-winded, flatulency takes place, and the air which is accumulated in the intestines, makes its escape backwards whenever the animal coughs. From this circumstance arose the ridiculous custom of nitking an artificial or supplementary anus, by dividing the sphincter ani, with a view to let the wind escape more readily.

Horses that are great feeders never breathe freely until they have gone a mile or two, or begin to sweat; but many of this description are sometimes stouter horses in constitution, and able to perform more work, than others that do not labour under the same difficulty. The variation of the atmosphere will also have considerable influence on respiration. 'Thus a horse, being brought out of the stable in a cold foggy morning, will agitate his nostrils so as to produce a kind of half snorting sound at erery action of his lungs. But it would be unfair to deem either of the abore cases as constituting unsoundness. 


\section{4}

It is, nevertheless, very difficult to draw the line in regard to the marketable state of a horse when affected with a cough; for certainly the purchaser incurs some risk; and a horse, with a cough, may continue sound in his lungs in the hands of one person, and yet become brokenwinded in the hands of another. It seems unreasonable that a purchaser, buying a horse affected with a cough, should return him, at any considerable length of time after the purchase, merely because he still continued to cough, although not broken-winded. By a parity of reasoning, a horse may be sold with a contracted hoof, and yet not be lame; but it would surely be unreasonable to return him, at the end of six months (although not lame) mercly because he had a contracted hoof.

A person selling a horse with a cough, might be required to give a warranty against his becoming broken-winded, in a given length of time; but even in that case he would not be bound to take the horse again, except he were positively broken-winded at the expiration of the term of the waranty, although the cough might continue to exist in the same degree as it did at the time of sale. There are very few horses that do not cough, more or less, when taken up from grass: they are very subject, also, at particular seasons of the year, to sore 


\section{5}

throats, and slight inflammatory attacks on the lungs. But all these defects are but temporary, and may be removed by timely care and attention. On the whole, therefore, it appears very fair to conclude, that, if a horse be not brokenwinded at the time of sale, he should be considered as a sound horse, as far as regards the state of his lungs, and not liable to be returned for having a cough. There is, however, another kind of diseased respiration, denominated

\section{ROARING;}

Which consists in the production of a sound similar to, though considerably louder, than the wheezing of the human being, when labouring under the paroxysm of an asthma. This sound never takes place, except the motion of the horse be quickened, but it increases with the increase of the pace. It is also very manifest, when the horse is going over a leap, at which time he generally gives a deep groan. Dealers have a method of ascertaining the existence of the disease, by striking the horse mier the belly with a whip, and tuming him suddenly round at the same time. If he groans during this process, they conclude that he is a roarer. The groaning is probably occasioned by the sudden contraction of the abdominal muscles, 


\section{6}

forcing air from the lungs with greater rapidity through the trachea, or windpipe, in consequence of the pain he feels from the stroke of the whip, as well as from the bending of the ribs, in the action of turning round in a small compass.

This disease prevails in a different degree in different subjects; in its commencement it is generally manifested by a whistling noise; but in its confirmed state, it is more sonorous, and resembles deep groaning. In either state, it is incurable, nor can there be any doubt of its rendering a horse unsound. There are certain circumstances, however, to be attended to, previously to deciding on the presence of the disease. A swelling of the parotid glands, or that part where the throat lash of the bridle passes lown, and which frequently arises from a complaint, called the strangles, will produce the same sound as roaring, if the animal be obliged to quicken his pace. Particular stages of a cold will also have the same effect. It is, therefore, necessary to ascertain that neither of the above causes exists, before any conclusive opinion can be formed with regard to a horse being a roarer.

The seat of the disease has hitherto remained in considerable obscurity. By some it has been ascribed to a partial obstruction in the nostrils, or to a thickening in the membranes of the 


\section{7}

mouth of the trachea, or windpipe, whilst others consider it solely as a disease of the lungs. Which of these theories is well-founded it is not easy to determine, as dissection of the dead subject does not always point out the sources of disease. A thickening of the membranes of the mouth of the trachea frequently occurs, probably from inflammation, arising from the custom of pinching that part of the windpipe, to ascertain if a horse be sound in his wind, and this circumstance may possibly be one cause of the disease.

\section{CRIB-BITING}

Is a defect which, when its consequences are duly considered, must be universally admitted as a cause of unsoundness. It consists of a habit which the animal acquires of laying hold of the manger with his teeth, and drawing forward his windpipe with a convulsive motion, accompanied with a slight grunting noise. During this action it is gencrally supposed that he sucks air into the stomach, and distends it to such an enormous size as to produce great inconvenience to him when put into a quick pace, which inconvenience never subsides until a great quantity of air is parted with from the nus or fundament. 
In my treatise on the Structure and Animal Economy of the Horse, I gave my reasons for doubting the fact of the wind being sucked into the stomach during the action of cribbiting; and, on a careful revision of the doctrine I held upon that subject, I have found no cause to alter my opinion. That an accumulation of air takes place in the stomach and intestines of horses of that description, is not to be clenied; but I believe that the air is collected from other causes, and is not sucked in at the mouth of the animal. In order, thoroughly, to comprehend the basis of this opinion, it is necessary to consider the anatomical form of the organs of respiration. The whole space of the atmosphere being filled with air, which constantly maintains its equilibrium, none of that air can be sucked in until a carity is formed for its reception: thus, no air can be sucked into the mouth, unless the chest opens and expands itself to receive it; that is to say, no air can be drawn inwards except at that period of the act of breathing distinguished by the term "inspiration." Now the mouth of the trachea or winclpipe is always open for the ingress and egress of air, except at the moment when food or liquids are swallowed, and pass over it into the asophagus or passige into the stomach. Therefore, supposing the animal swallowed the air coutained in his mouth by 
shutting his lips, the air being compressed would make its way for that part where it met the least resistance, and before the fauces could be sufficiently contracted to produce the act of swallowing, the air would be forced out at the nose or into the trachea. It is to be observed also, that the horse keeps his mouth open during the action of crib-biting, which he would not do if he performed the action of swallowing. On all these accounts, it may be fairly concluded that the animal does not suck air into the stomach during the action of crib-biting. It is most probable that the flatulence, to which horses of this description are so peculiarly subject, arises from imperfect digestion, a defect which must be considerably increased by the great loss of the saliva which runs out of the mouth by the parotid glands being compressed during the convulsive movement of the muscles of the larynx or origin of the windpipe. Be the cause however what it may, the inconrenience it occasions is so great, that no horse can be deemed sound and perfect that labours under that imperfection. Various methods have been adopted to prevent it, such as by buckling a strap round the upper part of the neck, covering the edge of the manger with an undressed sheepskin, or rubbing it with tar or any other offerisive liquid. 


\section{WIND SUCKING.}

This is a defect nearly of the same description as crib-biting, except that the horse neither bites nor rests his inouth against any substance during the action of wind-sucking. 'The horse genterally holds his head inwards, with his neck considerably bent, and appears, by the constriction of his lips, to suck wind; but, in this habit, as well as in that of erib-biting, no wind enters the stomach by the mouth, although horses of this description are subject to the same extraordinary flatulence as the former, and, on that account, are, in point of sale, equally objectionable.

\section{SHIVERING, OR NERVOUS AGITATION.}

This malady is denoted by the following appearances, viz. a considerable degree of inflexibility in the spine, or back bone, standing with the hind legs widle apart, and unsteady, and reeling when moved backwards, together with a perpetual elevation and tremulous motion of the tail. It is a disease of the spasmodic kind, but the cause of it is not yet thoroughly understood. At all events, it must depreciate a horse considerably in value; and by disqualifying him for useful purposes, consequently renders him unsound. 


\section{MEGRIMS, OR TEMPORARY APOPLEXY,}

Is a discase which cannot be discovered in a horse at any other period than when the symptoms are upon him. Horses affected with this discase will travel very well for a few miles; and suddenly, being seized with the complaint, will reel and drop down as if they were shot: a few minutes rest, however, generally restores them. It arises most probably from obstruction in the blood vessels of the brain, which, becoming extremely turgid by the increased circulation during quick motion, are unable to discharge their contents, and temporary apoplexy ensues, and which does not subside until the circulation is diminished, and the vessels are unloaded. It is impossible to detect the existence of this disease in the external appearance of the animal; therefore it is only by putting him to a brisk motion that it can be ascertained. The inconveniences arising from it are so palpable, that no doubt can be entertained of its rendering a horse unsound.

\section{WEAKNESS IN 'THE LOINS, COM- MONLY CALLED, RIGG'D IN THE BACK.}

This is a complaint which may arise from several causes; such as injury done to the spine 
or back bone, either by casting the horse to perform any surgical operation, or by turning suddenly in a narrow stall, or by resisting the pressure of a loaded carriage down hill, or from disease in the kidnies, or perhaps from chronic rheumatism. The external appearances are a stiffness in the back, a recling motion when going forwards, particularly in a circle, and little or no flexion in the hind quarters. The muscles of the loins, also, are generally shrunk or wasted. This wasting in the muscles of the loins is not the disease itself, but an effect of it, arising from a want of their regular action.

Inflammation and lameness in both hock joints at the same period, by producing nearly the same defect in the manner of going, is sometimes mistaken for lameness in the loins.

The disease is seldom cured, especially if any injury has been done to the back bone, in which case a preternatural enlargement and anchylosis takes place, uniting three or four of the joints of the back into one solid mass.

A horse labouring ninder this disease becomes almost totally useless; there can be no difficulty, therefore, in pronouncing lim to be unsound. 


\section{ON-THE AGE OF THE HORSE.}

Although the Age of a Horse cannot be classed among the Causes of Unsoundness, yet, as a Breach of Warranty may occur in regard to the Age, as well as to the Soundness of the Animal, I thought it would be of some Utility to give the Rules by which the Age is generally known.

Most Quadrupeds furnish some visible mark, whereby their age may be ascertained with tolerable certainty. Thus, the ox acquires annually an additional ring on his horn; the buck, an additional branch to the palm.

In the horse it is manifested by an alteration in the appearance of the teeth, and certain parts of the mouth. The horse possesses forty teeth, viz. twelve front teeth, or incisores, or nippers, twenty-four molares or grinders, and four canine teeth, which are called tushes: these last are wanting in the mare, except in some very few instances. Until five years old, the age of the horse is ascertained by the successive shedding of the twelve front tecth or incisores, which process begins at two years and a half old, and is carried on in the following order, namely, from two years and a half until three, he sheds 


\section{4}

the two middle teeth of the lower jaw, and also of the upper jaw. From three years and a half until four, he sheds the two next in both jaws. From four and a half until five, he sheds the two corner teeth of both jaws; and, at the same time, the canine teeth or tushes make their appearance. He is then no longer called a colt. At the upper surface or top of every tooth, there is a small black cavity, resembling the eye of a bean. This cavity in the teeth of the lower jaw furnishes the age from five years until seven; after which period it is usual to pronounce the horse to be aged, and deprived of any signs whereby his age can be ascertained. Nevertheless, the age may be calculated until twelve years by the same marks in the upper jaw, which remain after those in the lower jaw are worn out. This will be explained in its proper place. At five years old, the black marks or cavities in the two middle teeth of the lower jaw are filled up, and nearly disappear; for as they are shed the first, so do they lose their marks before any of the rest. At six years old, the black marks of the two second teeth are filled up in the same manner as the foregoing. At seven years old until eight, the marks of the corner teeth of the lower jaw fill up and disappear. At the same time the tushes, which antecedently to this period were concave in the surface next to the tongue, alter their shape, 
and become round or convex. The marks of the lower teeth being all obliterated at eight years old, it will be necessary to have recourse to the upper teeth, which undergo the same process as the lower teeth, except with this difference, namely, that they do not begin to fill up until all the lower teeth are deprived of their marks, and that there is an interval of two years between every tooth in the upper jaw, whereas in the lower jaw the interval is only one year. Thus, at eight, the cavities of the two middle teeth of the upper jaw begin to fill up. At ten, the cavities of the two next. And at twelve, the carities of the corner teeth are totally effaced. This rule, however, is subject to some variation in different horses, in proportion with the different qualities of their teeth, or on account of the habit of crib-biting, which wears away the teeth much faster than in their natural course. In addition to these appearances of the teeth, other signs of adranced age may be discorered, among which the following are the most remarkable: 'The roof of the mouth or palate is constructed with transverse ridges from one side to the other. These ridges are distant from each other about three quarters of an inch; their edges incline upwards, by which means they serve as points of contact for the food, and prevent it from falling out of the mouth during mastication. 


\section{6}

These ridges are large and distinct in a young horse, but become flatter and more level as the animal advances in years, and in very old horses they are nearly absorbed. The front teeth or incisores of both jaws, in a young horse, meet exactly in a line, and perpendicularly to each other. As the horse grows older, these teeth take a more horizontal direction, nearly in a line with the jaws, the upper teeth projecting very considerably over the lower teeth; at the same time the upper corner tooth forms a curve over the lower corner tooth. Furrows appear on their front surfaces, and their colour becomes ycllow and opaque. Other characteristics of age may be seen externally; for instance, the eyes sink in their orbits, the eye-lids become lean and wrinkled, and the cavity above the eye* appears more hollow. Gray hairs shoot out upon the forehead and the lower part of the mouth, the middle of the nose becomes indented by the long-continued pressure of the noseband of the head-collar, and the lips exhibit a lean and shrivelled appearance, the lower lip hanging considerably below the upper lip. The ears also drop more or less in a lateral direction. The exterual marks of old age, together with those of the teeth, the dealer in horses exerts his ingenuity to counteract.

* Thix carity, horverer, is somelimes deep in a young liorse. 
He therefore commences his operations by making an opening between the skin and cellular membrane, at a small distance above the eye, into which he introduces a quill, aud by blowing into it, fills up the cavity and gives it a plump appearance. He proceds next to furnish the corner tecth with the same marks which they possessed at seven years old. For this purpose he forms an artificial cavity in the hear of the tooth with an engraving tool, and gives it a black colour by burning it with a hot iron. This process, in the stable rucabulary, is called Bishoping. By such practices as these, an inexperienced person may be deceived; but by attending to the following observations, the imposition may be easily detected for although the dealer has it in his power to make maks or cavities in the corner teeth, yet he cannot alter their horizontal direction, nor restore them to the perpendicular approximation which is the attendant upon youth. Neither can he reproduce the prominence of the ridges of the roof of the mouth, nor furnish the tushes with their original concave surfaces. As it suits the purpose of the dealer to make an oid horse appear younger, so does he sometimes find it convenient to make a young horse appear older. A horse is more salcable at fire years old than at four, on which account the dealer attempts to produce an additional rear, by drawing the 
corner teeth before the natural period of their dropping out. The bars of the mouth are also cut to let the tushes protrude prematurely. But although the corner teeth are removed, and the protrusion of the new teeth is thereby somewhat accelerated, yet it is an unerring rule, that the animal has not attained his fifth year until the. corner teeth, both of the upper and lower jaw, are complete in their size and appearance, and the marks of the niddle teeth begin to fill up. The tushes also should rise considerably above the jaw.

It is difficult to discover with accuracy the age of crib-biters, and horses whose teeth are extremely hard; the former lose the marks of their teeth before their usual period, the latter retain them long after the age of seven years. In examining a horse's mouth, it is necessary to look at both sides of it, as a considerable difference in the appearance frecuently occurs from the mastication of the food being performed on one side of the mouth only, in which case the teeth on that side of the jaw which has most friction, will be most forward in their alteration. 


\section{CONCLUSION.}

It has been frequentiy and truly remarked, that explanatory treatises on certain professional subjects, instead of elucidating those subjects, tend but to involve them in greater doubt and obscurity. Thus, such Works as "Evcry Man his cwn Lawyer," and "Every Man his own Physician," are supposed to have increased, instead of diminished, the practice of both those professions; and as it is not improbable that the same result may be anticipated from the present publication, I think it necessary to caution the Reader, not to consider this work as containing any legal decisions, but simply as a reference to the nature and seat of those diseases, which, in a commercial point of riew, render the horse unsound; and which, in the arguing of a horse cause, are so often perverted or misunderstood. No man, who duly reflects on the infinite variety of points that perpetually occur in legal questions, (a variety so infinite that even all the luge volumes of recorded cases are unequal to provide against it), will be foolish enough to go to law on no better grounds than the result of his own partial judgment, drawn from a strained 


\section{0}

comparison of his case with any of the arguments laid down in this treatise. But if any man choose to proceed in that course, and, (neglecting to avail himself of the opinion of those whose professional abilities better qualify them for the arduous task, ) acts upon false premises, surely I am not responsible for the consequences; for I again repeat, that this is not a treatise on the laws of horse-iealing, but simply a referential compendium of those diseases which give birth to disputes in buying or selling that animal.

In the execution of this design, I feel conscious that I have left much undone; but the difficulty of the undertaking must be my chief apology both for omissions and inaccuracies.

To those who estimate the value of a book by the number of pages it contains, the present work may perhaps appear defective in that respect. By adopting the modern art of bookmaking, I certainly could have swelled it out to much larger dimensions, but I considered that the principal desiderata, in treatises of this description, were brevity and perspicuity. Stich was the object I had in view: I trust that I have, in some measure, attained it. 


\section{SUPPLEMENT.}

As it might be deemed injudicious in the arrangement of the work, to confine all the cuts to the Dedication, and as it is the fashion to embellish literary productions with vignettes illustrative of the subject, I have added'another cut, in the form of a rignette, as is here represented.

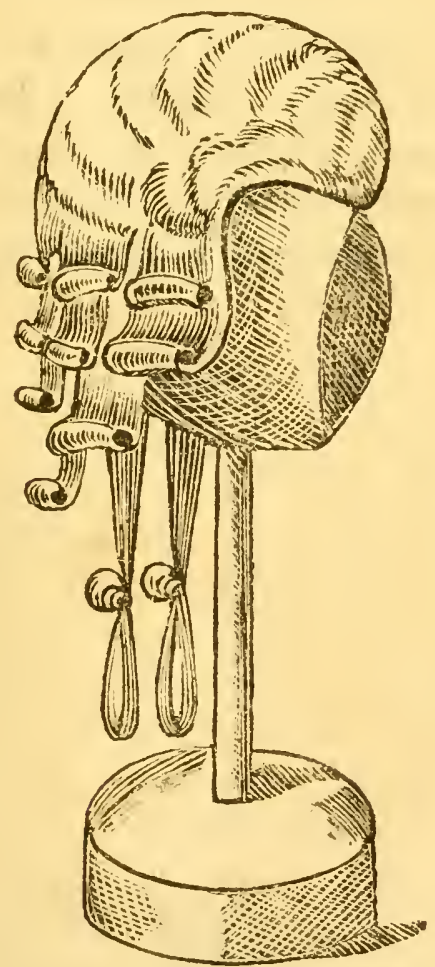




\section{( 82$)$}

For the correctness of the preceding portrait, I do not choose to pledge myself, although it was taken from the life; and as I have been desirous, throughout the Work, to observe a uniform impartiality in the dispensation of $\mathrm{my}$ tokens of veneration for the learned fraternity, I shall forbear mentioning the name of the Original, and leave it to the members of that learned profession to contend for the honour of the likeness. With regard to the engraving; I had some difficulty in deciding whether it would be most proper to execute it on wood or on brass. After some hesitation, I determined on adopting the former. The force of the impression, however, I leave to the judgment of the cognoscenti in those matters. 


\section{INDEX.}

Tre late Lord Mansfield's Opinion ........ page 13

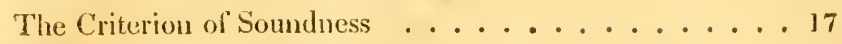

Miode of returning an unsound Horse ......... 21

Best Mode of obtaining a Varranty . . . . . . . . . 23

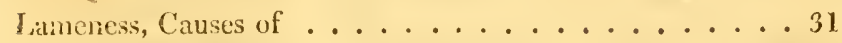

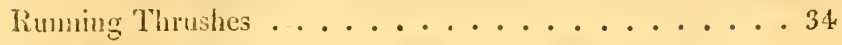

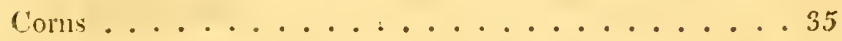

Sand Crack . . . . . . . . . . . . . . . . . . . . . . . . . . 36

False Quarter ....................... 37

Lameness in the Colfin Joint . . . . . . . . . . . . . . . . . . . . . 38

Osification of the Cartilages of the Foot ...... 39

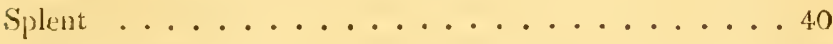

Hing Bolie . . . . . . . . . . . . . . . . . . . . . . . . . . . . . . . . .

Bone Spavin . . . . . . . . . . . . . . . . . . . . . . .

Strain of the Sheath of the Tendon . . . . . . . 46

Rupture of the Suspensor Ligaments, commonly called

Breaking Down of the Back Sinews ... . . . . . . . . 47

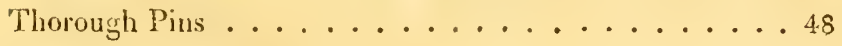

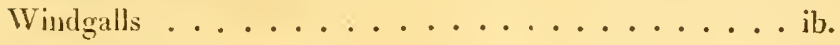

Blood spravin . . . . . . . . . . . . . . 49

Bog Spavin . . . . . . . . . . . . ib.

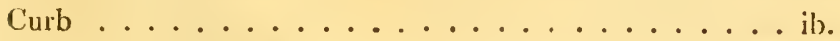

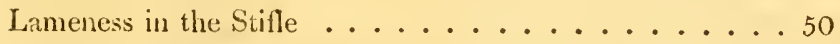

Lameness in the Whirl Bone ............ . ib.

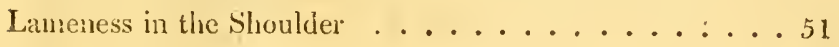

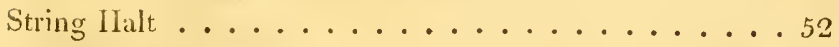

Imperfect Sight . . . . . . . . . . . . . . . . . . . . . .

Broken Wind . . . . . . . . . . . . . . . . . . . . . . . . . . . . . . .

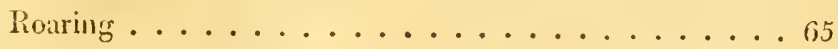

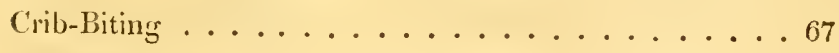

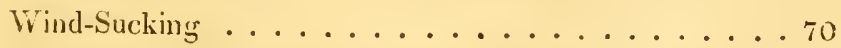

Shivering, or Nervous $\Lambda$ gitation . . . . . . . . . . ib.

Megrims, or temporary Apoplexy .......... 71

Weakness in the Loins, or Rigg'd in the Back ..... ib.

Age of the Horse ................. 73 



\section{This Day are published,}

And may be had of J. P. Lucas, 10, High Street, Birmingham; Longman and $\mathrm{Co}$. Paternoster Row, and Crosby and Co. Ludgate Hill, London; and all other Booksellers;

\section{A CONCISE HISTORY OF BIRMINGHAM; \\ containing an Account of its Ancient State, and the latest} Improvements; together with a Statement of the Arrival and Departure of the Mails, Stage Coaches, Waggons, Sic. the Whole forming a Complete Guide to the Inlabitant and Stranger. The Fourth Edition, embellished with an elegant View of the Town, a Plate of the Statue of Lord Nelson, from the Model of Westmacott, of London; and a Quarter Sheet Map of the Town. Price 3s. 6.l. extra Boards. Printed by R. Jabet, Herald Office, High Street, Birmingham.

An INQUIRY into the STRUCTURE and ANIMAL, CECONOMY of the HORSE; comprehending the Diseases to which his Limbs and Feet are subject; with proper Directions for Shoeing; and pointing out a Method for ascertaining his Age until his Twelfth Year. To which is added, an Attempt to explain the Laws of his Progressive Motion, on Mechanical and Anatomical Principles. Illustrated with 17 Plates. By RICHARD LAWRENCE, Veterinary Surgeon, of Birmingham. Price 1l. 1s. in Boards.

A CATALOGUE (Part II.) of New and Second-Hand SCARCE AND VALUABLE BOOKS, on Sale, at the very low Prices affixed to each Article, by J.P. LUCAS, Bookseller, \&c. 10, High Street, Birmingham. Price Gd. 
TIIE FRENCH STUDENT'S VADE MECUM, or INDISPENSABLE COMPANION; in which are displayed the different Cases of Persons and Things, as required by all the French Verlss and Adjectives,---the different Prepositions which they gorcm,---those reçuired by the Substantives,---and the different Moods which must follow the Conjunctions. By the Rer. P. C. LE VASSEUR, a Native of France, and Chaplain of the Cathedral of Lisieux. Price 7 s. Boards. Printed by R. Jabet, Herald Ofice, Birminghan.

\section{Opinions of the Hork.}

We are conrinced that it will be found vcry useful for Chuldien learning French, as it will answer the Purpuse of a Dictionary, or Vocabulary; at least in what relates to the Verbs and Particles, as well as the Idioms and Phrases. It is very properiy arranged in alphabetic Order, and renders the Government of Words plain to the Capacity of Youth. The present Treatise, therefore, must be a very conrenient Assistant to their Labours in Learning.

Anti-Jacobin, Aprit, 1809.

We do not thisk that the Title Page promises more than will be found in this little Work itsclf, which is a useful Book for reference, and will be of much Assistance to the Memory, particularly in writing gool French.

This Work is well adapted for the Improvement of those who are desirous both of writing, and of speaking the French Lauguage correctly.

Critical Rociew, April, 1809 : 
Weisiter : s......, many ur veterinary Medicine Cummings School of Veterinary Medicine at

Tufts University

200 Westboro Road

North Grafton, MA 01536 
